\title{
The Effect of Mindfulness on Heart Rate Control
}

\section{Citation}

Delizonna, Laura L., Ryan P. Williams, and Ellen J. Langer. 2009. The effect of mindfulness on heart rate control. Journal of Adult Development 16(2): 61-65.

\section{Published Version}

http://dx.doi.org/10.1007/s10804-009-9050-6

\section{Permanent link}

http://nrs.harvard.edu/urn-3:HUL.InstRepos:3196008

\section{Terms of Use}

This article was downloaded from Harvard University's DASH repository, and is made available under the terms and conditions applicable to Other Posted Material, as set forth at http:// nrs.harvard.edu/urn-3:HUL.InstRepos:dash.current.terms-of-use\#LAA

\section{Share Your Story}

The Harvard community has made this article openly available.

Please share how this access benefits you. Submit a story.

Accessibility 


\title{
The Effect of Mindfulness on Heart Rate Control
}

\author{
Laura L. Delizonna · Ryan P. Williams • \\ Ellen J. Langer
}

Published online: 7 February 2009

(C) Springer Science+Business Media, LLC 2009

\begin{abstract}
An experiment was conducted to test the hypothesis that mindful attention to change regarding heart rate (HR) would result in greater control over HR. Experimental groups monitored the changing or stable nature of HR, respectively. All participants' HR slowed during the decrease phase. Participants whose attention was directed to the stable nature of HR performed the worst on the increase phase of the HR control task. These results suggest that mindfulness, instantiated here as attention to variability, is a means to increasing control.
\end{abstract}

Keywords Mindfulness - Mindlessness .

Heart rate control · Mindful attention

"Change alone is unchanging."

-Heraclitus (c. 535-c. 475 B.C.)

\section{Introduction}

Despite the fact that virtually everyone pays lip service to the idea that nothing stays the same, 30 years of research suggests that it is common and more often than not,

L. L. Delizonna $(\bowtie)$

582 Market St., Ste. 1001, San Francisco, CA 94104, USA

e-mail: laura@drdelizonna.com

R. P. Williams

Stanford University, Stanford, CA, USA

E. J. Langer

Harvard University, Cambridge, MA, USA debilitating, to approach situations mindlessly as if they were unchanging (for reviews, see Langer 1997, 2005; Langer and Moldoveanu 2000). Mindfulness, defined as the process of actively noticing new things or creating novel distinctions, on the other hand, improves performance (e.g., Langer and Chanowitz 1981; Gardner and Moore 2004; Langer and Imber 1979; Ritchart and Langer 1997), relationship satisfaction (e.g., Burpee and Langer 2005), creativity (e.g., Langer and Piper 1987; Langer et al. 1989) and health (e.g., Langer and Rodin 1976; Rodin and Langer 1977; Alexander et al. 1989; Cioffi 1993; Crum and Langer 2007; Williams et al. 2000). In each of these studies, relatively simple instructions or minor contextual changes prompted individuals to pay mindful attention to salient information, problem solve more effectively and accurately, and modify their mindsets (Crum and Langer 2007; Langer and Piper 1987). The present investigation was an attempt to investigate if mindfully viewing a bodily process that is typically seen to be relatively unchanging (on a daily basis) as variable instead influences health-related behavior. The effect of noticing fluctuations in heart rate (HR) on the ability to control HR was assessed (Fig. 1).

The tendency to approach situations as if they were unchanging may be particularly problematic in physical health, because the hallmark of healthy functioning at a biological and physiological level is systemic variability (Giardino et al. 2000). Over the last several years, researchers have coined a new phrase to establish the role of variability in the human physiological cycle: allostasis. In contrast to the older term homeostasis, allostasis denotes that body systems do not stay the same throughout a diurnal cycle; rather, they vary with activity and time, allowing the body to continually react to external or internal stimuli (McEwen and Wingfield 2003; Korte et al. 


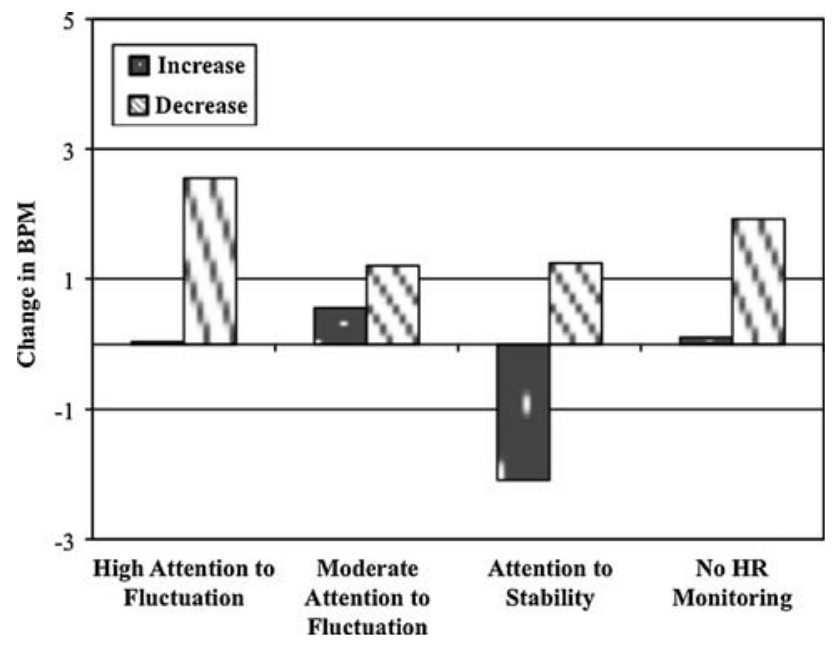

Fig. 1 Means for HR control on the bi-directional task by instruction group

2005; Sapolsky 2007). Assuming that blood pressure, HR, or other bodily processes are relatively static in nature is mindless.

The current study explored how to influence the ability to control a bodily process in the absence of process specific instruction, training, or prior experience. It was expected that mindful participants would spontaneously derive strategies for changing HR. The degree to which participants understood HR as stable or fluctuating was manipulated by directing their attention to the natural fluctuations that occur throughout a day or by directing their attention to times when HR would be similar from one day to the next (i.e., while in a restful state).

HR control was selected due to its importance, feasibility, and generalizability. First, HR is a self-regulatory behavior that can be measured both objectively and subjectively in the laboratory. Second, HR control is prominent in behavioral medicine and treatment interventions relating to stress management, cardiac rehabilitation (e.g. Moravec 2008), and anxiety and depressive disorders (Gorman and Sloan 2000). It is particularly relevant to anxiety disorders that emerge from a misinterpretation of normal cardiac symptoms, such as in panic disorder, noncardiac chest pain, and hypochondriasis. Third, perceptions relating to HR are likely to be applicable to other healthrelated perceptions (Pennebaker 1981).

Decades ago studies showed that individuals differ in their ability to regulate HR (Carroll 1979; Kato 1975). Studies of factors such as cardiac perception (Gannon 1980; McFarland 1975), imagery vividness (Carroll et al. 1979), state anxiety (Bouchard 1976), and locus of control HR (Gatchel 1975), however, failed to convincingly explain performance differences. In contrast, isometric exercises and the slowing or speeding of respiration rates are highly effective in controlling HR (Brener et al. 1969; Carroll et al. 1979; Carroll and Rhys-Davies 1979; Johnston 1976; McFarland 1975).

In the current investigation, we predicted that mindful attention to heart-rate variability would result in greater control over heart rate. We expected greater control in the increase phase, in particular, due to the widespread popularity of short-term relaxation/breathing exercises that are known to decrease heart rate.

\section{Method \\ Participants}

Seventy-five staff members and students (M:F breakdown, mean, SD) were recruited from both a northern California hospital and a private university campus. The final data set included only 43 of the 75 participants because 32 participants were unable to follow the protocol instructions explained below. This population was not significantly different from the underlying population initially recruited. The demographics of the final 43 participants are as follows: 27 females and 16 males, age range $=19-62$ years, $\mathrm{M}=31.2$ years, $S D=12.1$ years. Sixty-three percent of participants were Caucasian, 29\% Asian, 2\% AfricanAmerican, 2\% Hispanic, and 4\% other ethnicity. Individuals were paid $\$ 15$ for participation.

\section{Design and Procedure}

The experiment was conducted using a between-subjects experimental design to explore the effect of mindful attention on the ability to regulate actual HR and performance expectancies. Participants attended two sessions a week apart. A daily monitoring technique was used to increase attention to the natural fluctuations in HR. Participants were assigned in order of appearance to one of four instruction groups: (1) High Attention to HR Fluctuation, (2) Moderate Attention to HR Fluctuation, (3) Attention to HR Stability, and (4) No HR Monitoring. The instruction groups differed in the degree to which the daily monitoring required attention to HR fluctuations. The High Attention to HR Fluctuation group recorded HR in beats per minute (bpm) for $60 \mathrm{~s}$ every $3 \mathrm{~h}$ during waking hours, calculated the change in bpm between each reading, and recorded the type of activity they were engaged in at the time of the reading. Moderate Attention to HR Fluctuation group recorded HR in bpm for $60 \mathrm{~s}$ twice per day at predesignated times, which were provided by the experimenter on the monitoring forms. The times were different each day (e.g., 3 PM and 7 PM on day 1, 10 AM and 5 PM on day 2, 9 AM and 12 PM on day 3, etc.). They also calculated the 
change in bpm between each HR reading and recorded the type of activity they were engaged in at the time of the reading. The Attention to HR Stability group recorded HR twice per day, at the same time each day when HR was expected to be relatively stable; upon waking and just before sleeping. They also recorded what they were doing at the time of the reading, but they did not calculate the difference between readings. The No HR Monitoring group recorded the type of activity they were engaged in every $3 \mathrm{~h}$ during the day; they did not record HR.

\section{HR Control Task}

After the 1-week HR or activity monitoring intervention, participants attempted to control their HR in the laboratory while wearing a Polar HR monitor. In a bi-directional HR control task based on McFarland's (1975) task, participants attempted to increase and decrease their HR for $50 \mathrm{~s}$, respectively, with a 30-s baseline period between each trial for a total of 10 trials. Successful performance on the increase phase is showing a "retard to decrease" rather than a significant speeding of HR (see White et al. 1977). Through an intercom, they were instructed "Use your mind to change heart rate," (cognitive intervention) and were told not to intentionally change muscle tension or breathing (physical intervention). During debriefing, participants were asked if a physical strategy was used during the task. ${ }^{1}$

\section{Data Analysis}

Change scores on the increase phase of the bi-directional task were calculated from the mean bpm during the increase trial minus mean baseline. This was averaged from 5 trials. Change scores on the decrease phase of the bidirectional task were calculated from the mean baseline minus the mean bpm during the decrease trial, which was also averaged from 5 trials. Data from participants who reported using physical strategies to control HR were excluded from analyses.

\footnotetext{
1 The 32 participants whose data were excluded from analyses, because they reported that they had engaged in physical intervention strategies in order to adjust their heart rate and, thus, had not followed instructions. These participants' performance showed that they were able to change their HR significantly more than the other groups, which would be expected since physical intervention strategies alter HR substantially (e.g., an increased respiration rate dramatically increases HR).
}

\section{Results}

The Effects of HR Monitoring Instructions on Ability to Control HR

\section{HR Increase}

A one-way between-groups (High Attention to HR Fluctuation, Moderate Attention to HR Fluctuation, Attention to HR Stability, and No HR Monitoring) ANOVA with planned comparisons was conducted to compare the effect of attending to HR fluctuations on the ability to increase HR (mean change during all increase trials of the bidirectional HR regulation task). There was a significant difference between the groups on voluntary increase of HR $[F(3,36)=3.54, p=.02$, ETA $=.23]$. The effect size indicated a large difference in mean scores between groups (Cohen 1988). Planned comparison analyses (based on a priori hypotheses) indicated that the means for the High Attention to Fluctuation group were significantly different from Attention to Stability group $\left[M_{\text {HiFluct }}=.04\right.$, $S D=2.17 ; \quad M_{\mathrm{Stab}}=-2.09, \quad S D=2.50 ; \quad t(36)=3.54$, $p=.04]$. An inspection of means reveals that individuals in the Attention to Stability group generally decreased HR when attempting to increase HR. The other groups were not significantly different.

\section{HR Decrease}

A one-way between-groups ANOVA was conducted to compare group differences in the ability to decrease HR. The independent variable was the group and the dependent variable was the mean change in HR during the decrease phase of the HR control task (mean change during all decrease trials of the bi-directional HR regulation task). There was no significant difference in voluntary decrease of $\mathrm{HR}$ between the four groups $\left[M_{\text {HiFluct }}=2.55\right.$, $S D=2.07 ; M_{\text {ModFluct }}=1.20, S D=3.34 ; M_{\text {Stab }}=1.24$, $S D=2.33 ; M_{\text {NoMon }}=1.92, S D=1.32 ; F(3,35)=.69$, $p=.56]^{2}$

\footnotetext{
${ }^{2}$ Limitations: The small sample size weakened the power to detect differences between conditions. It is notable, however, that significant findings were identified even with a small sample size. The attrition rates were relatively high in this study, with approximately 1 in 4 participants failing to return to the second session. It is likely that the compensation amount was insufficient to motivate some participants to satisfy the study's requirements. Individuals who did follow through with the study's requirements may have been especially motivated. Self-regulation techniques are generally applied to a clinical population who are seeking to alleviate some type of distressful symptom and therefore highly motivated.
} 


\section{Discussion}

Attending to HR Fluctuations and HR Control

This study generated findings consistent with our hypothesis that mindful attention to the variability in one's heart rate enables more regulatory control over heart rate. The findings showed that the group that monitored the stability of HR performed significantly worse than the group that monitored the frequent fluctuations in HR. Further, this was the only group unable to control HR in the increase direction. Interestingly, no other differences between the experimental groups were found. Overall, these findings suggest the idea that mindlessly viewing a bodily process as stable inhibits one's ability to self-regulate. As mentioned earlier, significant results were found only in the increase phase of the experimental protocol. Not surprisingly, all groups showed a slowing of HR during the decrease phase, as HR naturally slows without activity. Successful performance on the increase phase was demonstrating a "retard to decrease" rather than a significant speeding of HR. While this effect may appear counterintuitive, the increase phase is considered a more accurate test of voluntary HR control (see White et al. 1977).

There are multiple implications of these results. First, this study provides supportive data for the premise of mindfulness as a working strategy for emotion regulation. Three decades ago, Langer et al. (1975) showed that mindfulness may reduce stress. A recent study by Low et al. (2008) illustrated that individuals who reflect on an stressful experience through acceptance-focused writing have more efficient control over their heart rate than individuals who reflect through an evaluative method. Gross and colleagues (Gross 2002; Gross and Levenson 1997) also have examined the effects of cognitive reappraisal in the context of emotion regulation and revealed that cognitive strategies are the most efficient methods of positive emotion regulation. The mindfulness training in this study may provide insight to a requisite for employing an emotion regulation strategy. Noticing that an internal system is not fixed but instead is fluctuating may be critical for effortful regulation of that system. Without this realization the individual may not be open to the possibility that the system can be regulated.

Besides the support for emotion regulatory strategies, this study adds to previous studies (e.g. Grossman et al. 2004; Langer 1989) that show mindfulness as a conduit for improved health. This investigation tested a new way to provoke mindfulness and did so regarding a measure, HR, not previously tested in this regard. According to Pennebaker (1981), perceptions relating to HR are often generalizable to many other health-related factors. Thus, the mindfulness technique employed here may be beneficial to enhancing control of other bodily symptoms. These findings may be relevant to the management of Reynaud's disease, migraine headaches, and poor circulation, for example. Whether a patient mindlessly views a physical symptom as stable or mindfully attends to variability could have important implications for the management of that symptom, and thus more generally for their health.

Lastly, this research illustrates a core component of Langer's mindfulness paradigm: all mindfulness requires is a switch in general cognition to making novel distinctions-noticing change. Over the last several years, many studies (e.g. dePascalis et al. 1991; Moravec 2008) have considered the use of biofeedback in regulating heart rate. The principal method of controlling heart rate in biofeedback trials is visual confirmation by electrocardiogram (ECG). By not using visual confirmation in this study, we illustrated that individuals can regulate their heart rate through simple mindful attention. Given the expense and time required in acquiring both equipment and technological support for ECG trials, it appears that just promoting mindfulness can efficiently help to decrease heart rate. And as the world continues to battle the problems of heart disease, a simple method to reduce overall stress on the heart may be important.

Participants were excluded if there was any indication or mention of physical strategies, because it is likely that respiration rates and skeletal strategies would easily override the subtle effects of cognitive factors, which were of primary interest. The large number of individuals who indicated use of physical strategies must be considered when interpreting these findings. Without using a paced respirator to control for respiration rates, respiratory changes pose limitations to the interpretations of this and other studies' findings. Most studies that instruct participants to use mental strategies to control HR do not report using paced respirators or attempts to assess for noncompliance with strategy instructions. This raises question to the effect of skeletal strategies in these studies and further complicates comparison of findings across studies.

\section{References}

Alexander, C. N., Chandler, H. M., Langer, E. J., Newman, R. I., \& Davies, J. L. (1989). Transcendental meditation, mindfulness and longevity: an experimental study with the elderly. Journal of Personality and Social Development, 57(6), 950-964.

Bouchard, C. (1976). Voluntary control of heart rate in humans. Canadian Psychological Review, 17(3), 182-195.

Brener, J., Kleinman, R., \& Goesling, W. J. (1969). The effects of different exposures to augmented sensory feedback on the control of heart rate. Psychophysiology, 5, 510-516.

Burpee, L., \& Langer, E. (2005). Mindfulness and marital satisfaction. Journal of Adult Development, 12(1), 43-51.

Carroll, D. (1979). Voluntary heart rate control: The role of individual differences. Biological Psychology, 8(2), 182-195. 
Carroll, D., Baker, J., \& Preston, M. (1979). Individual differences in visual imaging and the voluntary control of heart rate. British Journal of Psychology, 70, 39-49.

Carroll, D., \& Rhys-Davies, L. (1979). Heart rate changes with exercise and voluntary heart rate acceleration. Biological Psychology, 8(4), 241-252.

Cioffi, D. (1993). Beyond attentional strategies: A cognitive-perceptual model of somatic interpretation. Psychological Bulletin, 109(1), 25-41.

Crum, A. J., \& Langer, E. L. (2007). Mind-set matters: Exercise and the placebo effect. Psychological Science, 18(2), 165-171.

dePascalis, V., Palumbo, G., \& Ronchitelli, V. (1991). Heartbeat perception, instructions, and biofeedback in the control of heart rate. International Journal of Psychophysiology, 11, 179-193.

Gannon, L. R. (1980). Cardiac perception and the voluntary control heart rate. Physiological Psychology, 8(4), 509-514.

Gardner, F. L., \& Moore, Z. E. (2004). A mindfulness-acceptancecommitment-based approach to athletic performance enhancement: Theoretical considerations. Behavior Therapy, 35(4), 707-723.

Gatchel, R. J. (1975). Locus of control and voluntary heart-rate change. Journal of Personality Assessment, 39(6), 634-637.

Giardino, N. D., Lehrer, P. M., \& Feldman, J. M. (2000). The role of oscillations in self-regulation: Their contribution to homeostasis. Stress and Health, 13, 27-51.

Gorman, J. M., \& Sloan, R. P. (2000). Heart rate variability in depressive and anxiety disorders: Depression as a risk factor for cardiovascular and cerebrovascular disease. American Heart Journal, 140(4), S77-S83.

Gross, J. J. (2002). Emotion regulation: Affective, cognitive and social consequences. Psychophysiology, 39, 281-291.

Gross, J. J., \& Levenson, R. W. (1997). Hiding feelings: The acute effects of inhibiting negative and positive emotion. Journal of Abnormal Psychology, 106(1), 95-103.

Grossman, P., Niemann, L., Schmidt, S., \& Walach, H. (2004). Mindfulness-based stress reduction and health benefits: A metaanalysis. Journal of Psychosomatic Research, 57, 35-43.

Johnston, D. (1976). Criterion level and instructional effects in the voluntary control of heart rate. Biological Psychology, 4(1), $1-17$.

Kato, T. (1975). Voluntary control of heart rate with and without augmented external feedback. Tohoku Psychologica Folia, 34(1), 78-87 (from PsychINFO: abstract).

Korte, S. M., Koolhaus, J. M., Wingfield, J. C., \& McEwen, B. S. (2005). The Darwinian concept of stress: Benefits of allostasis and costs of allostatic load and the trade-offs in health and disease. Neuroscience and Biobehavioral Reviews, 29, 3-38.

Langer, E. (1989). Mindfulness. Reading, MA: Addison-Wesley.

Langer, E. (1997). The power of mindful learning. Reading, MA: Addison-Wesley.

Langer, E. (2005). On becoming an artist. New York: Ballantine Books.

Langer, E. J., \& Chanowitz, B. (1981). Premature cognitive commitment. Journal of Personality and Social Psychology, 14(4), 1051-1063.
Langer, E., Hatem, M., Joss, J., \& Howell, M. (1989). Conditional teaching and mindful learning: The role of uncertainty in education. Creativity Research Journal, 2, 139-150.

Langer, E. J., \& Imber, L. G. (1979). When practice makes imperfect: Debilitating effects of overlearning. Journal of Personality and Social Psychology, 37(11), 2014-2024.

Langer, E., Janis, I., \& Wolfer, J. (1975). Reduction of psychological stress in surgical patients. Journal of Experimental Social Psychology, 11, 155-165.

Langer, E. J., \& Moldoveanu, M. (2000). The construct of mindfulness. Journal of Social Issues, 56(1), 1-9.

Langer, E. J., \& Piper, A. I. (1987). The prevention of mindlessness. Journal of Personality and Social Psychology, 53, 280-287.

Langer, E., \& Rodin, J. (1976). The effects of enhanced personal responsibility for the aged: A field experiment in and institutional setting. Journal of Personality and Social Psychology, 34, 191-198.

Low, C. A., Stanton, A. L., \& Bower, J. E. (2008). Effects of acceptance-oriented versus evaluative emotional processing on heart rate recovery and habituation. Emotion, 8(3), 419-424.

McEwen, B. S., \& Wingfield, J. C. (2003). The concept of allostasis in biology and biomedicine. Hormones and Behavior, 43, 2-15.

McFarland, R. A. (1975). Heart rate perception and heart rate control. Psychophysiology, 12, 402-405.

Moravec, C. S. (2008). Biofeedback therapy in cardiovascular disease: Rationale and research overview. Cleveland Clinic Journal of Medicine, 75(S2), S35-S38.

Pennebaker, J. W. (1981). Stimulus characteristic influencing estimation of heart rate. Psychophysiology, 18(5), 540-548.

Ritchart, R., \& Langer, E. (1997). Teaching mathematical procedures mindfully: Exploring the conditional presentation of information in mathematics. In J. A. Dossey, J. O. Swafford, M. Parmantie, \& A. E. Dossey (Eds.), Proceedings of the nineteenth annual meeting of the North American chapter of the international group for the psychology of mathematics education. Columbus, $\mathrm{OH}$ : ERIC Clearinghouse for Science Mathematics, and Environmental Education.

Rodin, J., \& Langer, E. (1977). Long-term effects of a controlrelevant intervention among the institutionalized aged. Journal of Personality and Social Psychology, 35, 897-902.

Sapolsky, R. M. (2007). Stress, stress-related disease, and emotion regulation. In J. J. Gross (Ed.), Handbook of emotion regulation (pp. 606-616). New York: Guilford.

White, T., Holmes, D., \& Bennett, D. (1977). Effects of instructions, biofeedback, and cognitive activities on heart rate control. Journal of Experimental Psychology: Human Learning \& Memory, 3(4), 477-484.

Williams, J. E., Teasdale, J. D., Segal, Z. V., \& Soulsby, J. (2000). Mindfulness-based cognitive therapy reduces overgeneral autobiographical memory in formerly depressed patients. Journal of Abnormal Psychology, 109(1), 150-155. 